\title{
Police Interrogation: Repeating as a Way of Challenging and Expressing Scepticism
}

\author{
Marijana Cerović, PhD \\ Faculty of Philosophy-Nikšić Danila Bojovića bb, 81400 Nikšić \\ Email: cmarijana_2000@yahoo.com
}

Doi:10.5901/mjss.2014.v5n13p113

\begin{abstract}
Using the method of Conversation Analysis this paper explores an interactional technique of challenging or expressing scepticism in the context of police interrogation. The sequence starts with questioning officers' turns, following which suspects produce answers which are evasive, invoke honesty, give resistance or try to obstruct the line of interrogation. The detectives treat these kinds of answers from the suspects, among other ways, by means of full or partial repeats of the received answer. The repeats have some properties of repair initiation as they indicate that there is some sort of trouble with the received answer, however, since they express detectives' scepticism and non-acceptance of the received answer, rather than looking into repairing the trouble, they have a potentially damaging effect. This technique of the detectives, used to undermine the suspects' position creates a general atmosphere of intimidation, which is revealed through suspects' post-repeat turns. Responses to such detectives' turns can be defensive, the defensiveness being expressed by no response from the suspect, a number of defensive elements in the response turn design, overlapping, defending the initial position and so on.
\end{abstract}

Keywords: Interrogation, suspect, questioning officer, repeats, scepticism, challenging

\section{Introduction}

This paper deals with an interactional practice which occurs with some regularity in the police interviews with suspects. The practice is realized through the linguistic device of repetition; more precisely, it is a repetition by the questioning officer of the response provided by the questioned party. The way this phenomenon works is that the detective asks a question, the suspect answers, but as the detective finds this answer unsatisfactory in certain way, he repeats a part or the whole of the received answer in order to challenge it and potentially have the suspect review it.

Repeats can be associated with the repair phenomenon as one of the devices for doing repair is repetition of a part of the previous turn. Repair is usually described as an interactional device which indicates some kind of trouble, a problem in speaking, hearing or understanding the talk (Schegloff, 2000). In the following extract, taken from Schegloff et al. (1977) Al repeats a single lexical unit from the previous turn, thereby signalling that Ken has committed some kind of error:

\section{Extract 1}

01 Ken:'E likes that waider over there,

02 Al: Wait-er?

03 Ken: Waitress, sorry,

04 Al: 'At's bedder

Taken from Schegloff et al. (1977, p. 377)

$\mathrm{Al}$ is, therefore, trying to fix the trouble, and in order to do so, he signals that there is a problem by means of the linguistic device of repetition. As one can see, in line 03 Ken registers Al's repair initiator, repairs 'waiter' into 'waitress' and resolves the trouble. A similar non-acceptance of the received answer is also found in the repeats studied in this paper. When the detectives repeat what the suspect has said, they are not accepting the received answer as having been a valid one. However, what is different about these repeat sequences is that the suspect never gets to repair whatever is indicated as repairable.

\section{Data and Methodology}

The method I am applying is Conversation Analysis (CA). The interactional encounters used in this research include interviews with witnesses, damaged parties (for example a person reporting financial fraud), interviews with suspects who have admitted to their participation in a criminal activity and 'true interrogations' with parties suspected of having committed some crime, but who hold a position of innocence. There are 24 interviews ranging in length from 2.28 to 
61.01 minutes.

\title{
3. The Repeats Phenomenon
}

In the example to follow one can trace the basic features of the phenomenon. Extract 2 below is taken from a factory theft interview. Some expensive parts went missing from a factory and the detectives are questioning different factory workers as they believe that some of them might be involved.

\section{Extract 2}

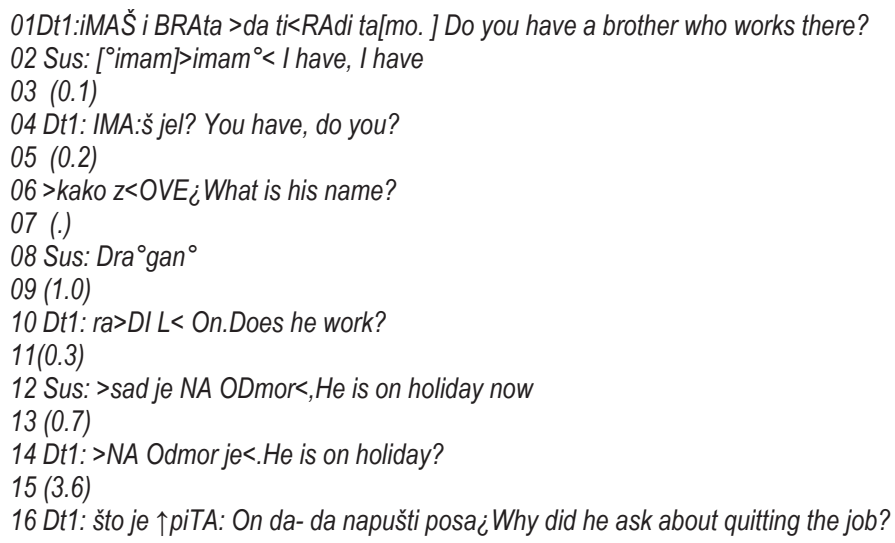

The detectives are here questioning the suspect, a mechanic in the factory, about his brother who works in the same factory in which the theft took place. There are two instances of repeats in this extract (lines 04 and 14), and the suspect does not get to respond to either of these. Because the repeat in line 04 has a tag 'jel'- 'is it', I will focus on the repeat in line 14 which is simple and more straightforward in form.

Although the detectives are familiar with the fact that the suspect has a brother and that the brother works in the same factory as the suspect (this gets to be revealed in line 16 when Dt1 asks 'Why did he ask about quitting the job?') they still question the suspect as if they do not have any of the information. After the suspect confirms he has got a brother in line 02, Dt1 produces a repeat of his answer 'IMAš jel?' which already signals that the 'brother topic' will be given a special treatment. Then, following a (0.2) pause in line 05 , Dt1 moves on to the name of the brother, and in line 10 he inquires if the suspect's brother works. In line 12 the suspect states that his brother is on holiday. One can note that this response is non-elliptical in form, which indicates that the suspect has analyzed the detective's prior turn as some kind of trouble. Following this indication of trouble, the detective produces a repeat 'he is on holiday?' in line 14 which, as one can note, is quite simple - the 'now' is omitted from the original suspect's turn and the auxiliary 'je' is postpositioned. Following the repeat, the detective leaves a space of (3.6) for the suspect to respond, but as the suspect does not find that a response is a relevant next, the detective pursues questioning. One can note that position-wise, the repeat from line 14 occurs in the third turn slot, after the detective has received an answer to his 'question' in the first position. By doing the repeat, Dt1 indicates that he has considered the received answer and has found it in some ways unacceptable. In line 16 Dt1 displays more explicitly why he has found the response to be unacceptable - the suspect has not mentioned the fact that the brother wants to quit his job (which is already familiar to Dt1), the dissembling of which might be an indication of the brother's culpability.

Having in mind the above given example, one can represent the basic repeat sequence in the following way:

\author{
Dt: question \\ Sus: answer \\ Dt: partial/full repeat of the suspect's answer
}

More precisely, the first speaker asks a 'question' (an interrogative or any other form that requires an 'answer' as a second pair part). The second speaker provides an answer as an appropriate SPP. In third position, then, the first speaker does some kind of repetition of the received answer.

Next to this basic repeat format, there are instances in which after repeating or partially repeating the suspect's answer, the detective produces some additional material in the same turn. The repeat in extract 3 , line 07 is a case in 
point.

\section{Extract 3}

01 Dt1: phhhh niti je bilo što sumljivo. kami $\downarrow n i: j e ~ p h h h h$ nor was there anything suspicious, yeah right

02 (0.4)

03 Sus: a okle sam zna:? Ko je zna:? And how could I know? Who knew?

$04(0.8)$

05 Sus: ${ }^{\circ}((\text { swears }))^{\circ}$

$06(1.0)$

07 Dt1: ko je zną (0.1)\znali ste VI: Bogo mi Who knew, you knew by God.

Extract 2 is taken from an interview with another suspect in the previously mentioned factory theft case. In line 01 the detective accuses the suspect, a security guard in the factory, that he knew something about the organization of the theft before the theft took place. The detective does the accusation in an indirect way, by 'Nor was there anything suspicious, yeah right', implying that something must have been suspicious. The suspect too defends himself in an indirect way, by a double interrogative construction 'And how could I know? who knew?' in line 03, followed by some swearing in line 05. In line 07 Dt1 does a partial repeat of the suspect's answer in line 03 - 'Who knew?' and then he adds a new element 'you knew for sure'. The repeat and the appended element together reinstate the accusation, previously made in line 01.

Looking across the different types of interviews in my data set, what becomes evident is an asymmetric distribution of the repeat phenomenon. It, first of all, emerges that the technique is utilized primarily by the detectives. The interlocutors in the 'subdued' position, i.e. the suspects/ witnesses do not use it as often, and in those cases when they do use it, the technique serves to counter challenge the open accusations from the detectives.

Another observation is that the phenomenon occurs only in those interviews in the data set in which the questioned party is treated as a suspect. The technique does not occur in the interviews with those interlocutors who are treated only as witnesses, when citizens report a crime, nor in those cases in which the questioned party has admitted to their participation in a criminal activity. This uneven distribution strongly suggests that there is a contesting quality to this technique and that it is primarily used to facilitate some more dramatic activities, such as the activity of doubting. A similar undermining repeat practice can be found in trials, in cross-examinations of witnesses (see Drew, 1992, the case of a rape trial).

\section{Repeats - Sequence Pattern}

There are two principal sequential patterns of repeats and to each of them there is a variation, represented as patterns 1(a), 1(b) , 2(a) and 2(b) below. This makes four communicational strategies that the speakers can follow.
Pattern 1(a):
Dt: 'question'
Sus : answer
Dt: repeat of the suspect's answer
Sus: response to the repeat

A variation on the first repeat pattern can be presented as follows:
Pattern 1(b):
Dt: 'question'
Sus: answer
Dt: repeat
Sus: no response on the part of the suspect

The second interactional pattern can be represented as follows:
Pattern 2(a):
Dt: 'question'
Sus : answer
Dt: repeat of the answer + next component 

Pattern 2(b):
Dt1: 'question'
Sus: answer
Dt1: repeat of the answer
Dt2: next component

So far, I have shown possible variations of the repeat sequence pattern. The repeats' turn design can vary itself. These turns could either be full repeats, the fullness of the repeat reflects the fact that they echo the core of the received answer, but do not copy discourse markers such as 'well' or similar, and they almost invariably transpose personal pronouns or person reference morphological markers. Partial repeats copy only a part of the answerer's turn.

\section{Suspects' Initial Responses}

In the previous section I mentioned the fact that suspects' initial (repeated) responses can either be short or elaborate. Another feature of these responses is that they are non-elliptical in form. One can note that in the two extracts below, the highlighted suspect's responses are different in form. In extract 4, the response in line 03 is non- elliptical, non-elided, it is longer in form while it could have simply been a 'yes' or 'no'.

\section{Extract 4}

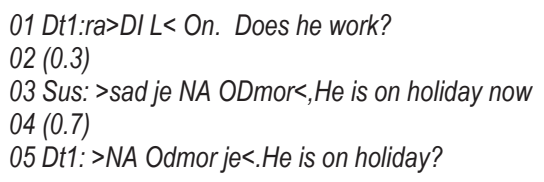

On the contrary, about twenty lines into the interview (Extract 5), the response in line 03 has an elliptical marker 'yes' + addition.

Extract 5

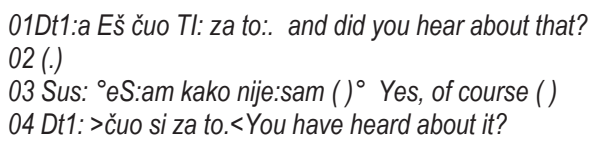

In his work on the structure of responding, Raymond (2000) shows how the omission of the overt 'yes' or 'no' in response to 'questions' does special interactional work. Raymond states that by answering 'yes' or 'no', speakers are complying with the terms of a FPP. By contrast, by omitting these markers in their response, speakers indicate they do not accept the terms of the FPP.

Thus, in extract 4, responding by 'he is on holiday now' to Dt1's inquiry in line 1 the suspect is signalling his noncompliance with the terms of the received question. First of all, saying 'no' would mean that the brother is unemployed, which would be untruthful. As the brother is on holiday, saying 'yes' would also in certain way be untruthful, so the suspect goes for the option 'he is on holiday now', 'now' indicating a contrast between a current and past/future state. The resistance of the suspects' initial responses can be seen in other examples. There is certain evasiveness in each of them: they are non-conforming and they claim a lack of knowledge about the crime they are being asked about. They can also be claiming non-involvement or invoking honesty. The described interactional techniques seem to be used by the suspects as to avoid their incrimination by the interrogators.

\section{Repeats - Expressions of Scepticism}

As already intimated, repeats can be associated with the repair phenomenon as one of the devices for doing repair is repetition of a part of the previous turn (Schegloff et al.., 1977; Schegloff, 2000). Other functions of repair by means of repeating are confirming or re-asserting the original version of the trouble source (Schegloff et al., 1977) and confirming the allusions by speakers in a more knowing position (Schegloff , 1996). Although sequentially different, a parallel can be made between the repeats in Schegoff's work and those treated in this chapter: they both appear in third turn positions and they both deal with something that is not overtly said - Schegloff's confirming repeats deal with the information conveyed inferentially; the repeats produced by the questioning officers in my data set with the information the suspect 
knows but resists to convey. By repeating a part or the whole of the suspect's answer the detectives imply that the suspect is not quite telling the truth.

Repeats can be seen as sceptical simply by the virtue of being repeats. However, sometimes there is an extra component added to the repeat, which supports and makes the challenge more direct and obvious. In extract 6 , one could see that in lines $01-10$ the suspect tries to slow down and block a particular line of interrogation (note lines 3 and 10).

\section{Extract 6}

01 Dt1:A JESte li se >sretali u kafanu?< reci mi And were you seeing each other in the tavern, tell me

02 (.)

03 Sus: $m:$ (0.1) KAd.Mmmm When?

$04(0.5)$

05 Dt1: PRlje no je ON Before he

06 (0.7)

07 Sus: n:e[: ] No

08 Dt1: [u]RADIO šta je uradio. did what he did

09 (0.8)

10 Sus: m:...... ' ${ }^{\circ}$ e sna:m.(0.1) <ne sjeća se.> ${ }^{\circ} \mathrm{mmm}$ I don't know, I don't remember

$11(0.8)$

12 Dt1: >NE sjećaš se< (.)>oli da t JA< podśetim; You don't remember? Shall I remind ya'?

In line 11 comes a longish pause and in line 12 the detective does the first undermining move, by producing a repeat 'You don't remember?'. The detective undermines the received answer by showing scepticism concerning the truthfulness of the received response. The attached interrogative 'Shall I remind ya'? intensifies the repeat which precedes it and expresses the challenge more overtly. While the repeat challenges by being sceptical, it does not provide any evidence for being such. The attached interrogative essentially shows the detective's epistemic position on which he based the challenge: the detective knows, presumably from the witness statements, if the suspect was meeting the other party in the tavern. 'Shall I remind ya?' is also heard as somewhat ironic. It almost serves as a transition from 'unsaid' to 'said' for it introduces an even more challenging story which reveals the details of the 'tavern encounters'.

\section{Suspects' Defensive Response to Repeats}

Conversation analysts hold that whatever a certain interactional device does in communication is best displayed in the way the interlocutors respond to it. Essentially, at the heart of CA is the fact that interlocutors constantly convey their understanding or analysis of what the co-participants said. The occurrence of a FPP requires an appropriate SPP. SPP necessarily displays how the speaker has analysed the first to which it responds. If a speaker responds to a FPP with an inappropriate SPP, the FPP speaker can see that he/she has not been properly understood and this opens a possibility for the FPP speaker's repair in the third-turn position. Sidnell $(2010$, p. 67) states: '... participants in conversation look to a next turn to see if and how they have been understood. As analysts we can exploit the same resource. This is sometimes called the next-turn proof procedure'. Applying the next turn proof procedure, one can note that a considerable degree of defensiveness is displayed in the recipients' responses to the repeat turns, i.e. they are perceived as aggressive, damaging devices.

As already mentioned, the suspect does not respond verbally to some of the repeats, no matter whether they stand on their own or they have an additional element attached. This can be noted in the already analysed extract 7 below.

Extract 7

01Dt1:iMAŠ i BRAta >da ti< RAdi ta[mo. ] Do you have a brother who works there?

02 Sus: ['imam ] imam $^{\circ}$ I have, I have

$03(0.1)$

04 Dt1: IMA:š jel? You have, is it?

$05(0.2)$

$06>$ kako $z<O V E_{i}$ What is his name?

Note that there is no verbal response after the repeat and the additional element in line 04 above. There is a $(0.2)$ pause in line 05 in which the suspect had a chance to come in. However, there is no attempt from the suspect to respond, unless he responded with a nod. 
As well as not responding to repeats, suspects can express resistance to the work done by the repeat in a more active fashion. In the following example, the detectives are questioning a factory security guard (the factory theft case). Extract 8

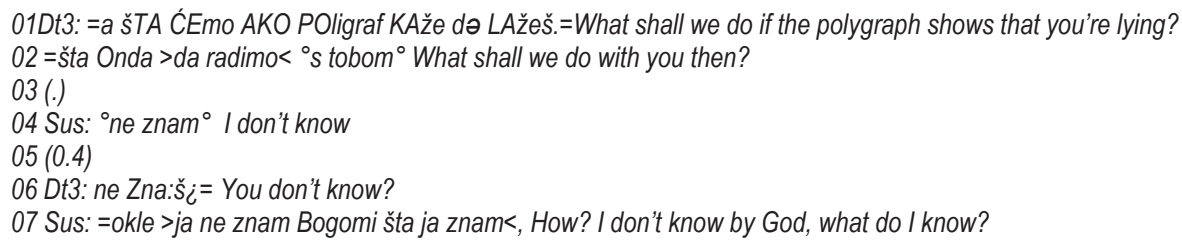

After the suspect states that he does not know what would happen if the polygraph shows that he is lying, Dt3 does a repeat of 'You don't know?' in line 06 . Note how the suspect has analysed the repeat: the suspect's response in line 07 is latched, there is no time between the detective's repeat and the suspect's response to it. Then, the design of the suspect's turn gives away defensiveness. The suspect treats the repeat as containing the proposition 'you know', i.e. as accusing him of lying, so he first does a direct negation of this proposition. He then produces an additional TCU 'what do I know?', an unanswerable challenging wh-interrogative, which also carries the implication 'I don't know'. This double rejection of the detective's implied accusation very much contributes to the response being perceived as defensive.

Repeats can follow and support other openly challenging turns. In such cases, the suspect can understand repeats as a way of reinstating an open challenge from the preceding talk. Suspects can overlap as a response to a repeat turn; they can also claim inability to be precise, which leaves them an option of not giving any definite response.

\section{Conclusion}

In this paper I have dealt with an interactional technique of challenging or expressing scepticism concerning the suspect's answer by the questioning officer. Looking at the suspects' initial answers to which the detectives respond by means of a repeat, one can note that they are in some way non-straightforward or detectives find them in some way unacceptable. These answers are non-elliptical, non-elided, claiming not to know or not to remember, they are evasive, invoking honesty, giving resistance and trying to obstruct the line of interrogation.

The detectives treat these kinds of answers from the suspects, among other ways, by means of a full or a partial repeat of the received answer. This is sometimes supported by a supplementary which tends to make the challenge expressed by a repeat more explicit. One has seen that the repeats have some properties of repair initiation as they indicate that there is some sort of trouble with the received answer and as, in a way, they are striving to reset the sequence and have the received answer amended. However, repeat sequences cannot be taken to be quite the same as repair. Since repeats express scepticism and non-acceptance of the received answer, and they have a potentially damaging effect, they unlike real repair, most often involve no repair on the suspect's initial answer. Instead, the suspect sticks to the previously taken position.

This technique of the detectives, used to undermine the suspects' position does create a general atmosphere of intimidation. This could be noted in the suspects' post-repeat turns. An examination of how suspects respond to the repeat turns has shown that they perceive them as threatening. We have seen how their responses to such detectives' turns can be defensive, the defensiveness being expressed by no response from the suspect, through a number of defensive elements in the response turn design, overlapping as to take over the turn, holding the same position since the suspects can perceive the repeat turns as reinstating the prior accusations and so on.

\section{References}

Drew, P. (1992). Contested evidence in courtroom cross-examination: the case of a trial for rape. In P. Drew, \& J. Heritage (Eds.), Talk at Work (pp. 470-521). Cambridge: Cambridge University Press.

Raymond, G. (2000). The structure of responding: type-conforming and non-conforming responses to yes/no type interrogatives. Ph.D. University of California, Los Angeles.

Schegloff, E. A. (1996). Confirming allusions: towards an empirical account of action. American Journal of Sociology, 104, $161-216$.

Schegloff, E. A. (2000). When 'others' initiate repair. Applied Linguistics, 21, 205-43.

Schegloff, E. A., Jefferson, G., \& Sacks, H. (1977). The preference for self-correction in the organization of repair in conversation. Language, 53, 361-82.

Sidnell, J. (2010). Conversation Analysis: An Introduction. Singapore: Wiley-Blackwell. 


\section{Transcription Key}

[] square brackets overlapping talk

= equals sign no discernible interval between turns (also used to show that the same person

continues speaking across an intervening line displaying overlapping talk

$<$ "greater than" sign "jump started" talk with loud onset

(0.5) time in parentheses intervals within or between talk (measured in tenths of a second)

(.) period in parentheses discernable pause or gap, too short to measure

Characteristics of speech delivery:

. period closing intonation

, comma slightly upward "continuing" intonation

? question mark rising intonation question

$¿$ inverted question mark rising intonation weaker than that indicated by a question mark

! exclamation mark animated tone

- hyphen/dash abrupt cut off of sound

: colon extension of preceding sound -- the more colons the greater the

extension

$\uparrow \downarrow$ up or down arrow marked rise or fall in intonation immediately following the arrow

here underlining emphasized relative to surrounding talk

HERE upper case louder relative to surrounding talk

${ }^{\circ}$ here ${ }^{\circ}$ degree signs softer relative to surrounding talk

$>$ this < speeded up or compressed relative to surrounding talk

$<$ this > slower or elongated relative to surrounding talk

hhh audible outbreath (no. of "h"s indicates length)

.hhh audible inbreath (no. of "h"s indicates length)

(h) audible aspirations in speech (e.g., laughter particles)

hah/heh/hih/hoh/huh all variants of laughter

( ) empty single parentheses transcriber unable to hear word

(bring) word(s) in single parentheses transcriber uncertain of hearing

((coughs)) word(s) in double parentheses transcriber"s comments on, or description of, sound: other audible sounds are represented as closely as possible in standard orthography,

e.g.,"tcht" for tongue click; "mcht" for a lip parting sound 